\title{
Nested Repetitive Structure Techniques in Examination Seating Number Allocation Process at UiTM Pulau Pinang Branch
}

\author{
Jamal Othman1*, Rozita Kadar1, Naemah Abdul Wahab \\ Department of Computer and Mathematical Sciences, \\ Universiti Teknologi MARA Cawangan Pulau Pinang, Malaysia \\ Corresponding author:*jamalothman@uitm.edu.my \\ Received Date: 22 July 2020 \\ Accepted Date: 5 October 2020
}

\begin{abstract}
Preparation of examination seating numbers during the final examination at UiTM Pulau Pinang branch is manually drafted and written by the examination unit staff on the class lists printed through the Student Integrated Managements Systems (SIMs). Process of assigning the seating number for each student takes couple of weeks and this task has become a challenging part for examination unit. Since the students' enrolments are linearly increasing every semester, the workloads among Examination Unit staffs become very burdensome in assigning the seating number. To automate the process of assigning the seating numbers, an algorithm was designed and constructed using the nested repetitive or looping structure techniques with JAVA programming language. Two tasks were identified in assigning the seating numbers; the first task was to set the examination seating number range with start and end numbers for each group of courses registered by the students and the subsequent task was to assign the seating number for each student accordingly by group seating number range as specified during the prior task without the violation or overlapping of seating numbers. The algorithm was tested using real data enrolments taken from SIMs for two semesters and resulted in positive effect especially on the reduction of stressfulness and zero erroneous allocation of the seating numbers.
\end{abstract}

Keywords: Nested Repetitive, Seating Numbers, SIMs, SDLC, EMS

\section{INTRODUCTION}

Generally, the Academic Affairs Department at UiTM Pulau Pinang branch is divided into three main units namely general administration, students' records and examination units. Examination unit is the most crucial unit in which its key functions involve the preparation of question paper, printing and packaging of question paper, handling examination operations and management of the overall students' marks (Quality, 2010; UiTM, 2016).

Handling examination operations involves several sub modules including the preparation of final examination schedules for each course, placement of examination venue process, printing and packaging of the question papers and the process of assigning invigilators at the examination halls (UiTM, 2016). Whenever the Department of Academic Evaluation from UiTM Shah Alam, Malaysia announce the examination schedules for each subject, staff at the examination unit will start preparing final examination operations. The earliest task is to allocate the venue of examination for each course. Once the venue is allocated and verified by the Assistant Registrar (Examination), the subsequent process is to arrange the examination seating number. The arrangement or allocation of the seating numbers is prepared manually for all courses and links to students' enrollment downloaded from the Student Integrated Management Systems (SIMs). This process is employed by two staff of Examination Unit assisted by the examination committee at UiTM Pulau Pinang Branch for 20 days of examination duration. This preparation continues until the examination ends. The examination seating number for each student is written manually one by one on the class list printed from SIMs by referring the range of seating numbers, which is also manually calculated during the prior task. 
The process of allocating the seating number is very cumbersome. For the staff who involved in the seating number allocation, it is tiring and exhausting. Quite a number of cases have been reported in the pass examinations whereby two students clashed in the same seat number. The seating numbers written on the class lists were different from the examination hall plan on seating number range sheets. As a result, it became very tough for the invigilators to control the examination halls and ensure proper examination environment under the standard operating procedure (SOP) or ISO 9001:2008. All these lead to examination defects and surely the credibility or integrity in handling of examination operations will be queried by the top management and more importantly, creates negative perceptions among students.

On average, the total numbers of students' enrolment at UiTM Pulau Pinang Branch are approximately 32,000 to 35,000 per semester. Imagine if the allocation of students' seating numbers with that total of enrolment need to be done manually by only two staffs for three week of examination duration, surely erroneous examination cannot be avoided. More time is required to prepare the examination timetable whenever the total enrollments of students are very large besides the diversified courses offered at the faculty or department levels (Bloomfield and McSharry, 1997). The task of examination seating number allocation in the examination halls cannot be excluded as it helps the students to determine the seat number for each course easily. Hence, this task needs to be done automatically to improve the smoothness and efficiency of the examination operations and create positive satisfaction among examination unit staff and examination committees.

Therefore, one technique or approach was introduced to automate the process of examination seating number allocation for each course taken by students. This process can be performed in less than a minute with a powerful coding. This way, the manual allocation of seating numbers for three weeks will be replaced by a powerful application and processed without the overlapping of similar seating numbers. With this enhancement, the staff will be able to avoid defects on examination operations and their credibility or integrity will not questionable. Techniques or algorithms of examination seating number allocation were traced, evaluated and customized according to the situation of Universiti Teknologi MARA at Pulau Pinang Branch.

The paper is organized as follows. The next section explores related works on allocation of examination seating numbers at present. The following section discusses on the proposed work that could contribute to the efficiency of the examination seating number allocation. Finally, the paper is concluded with several recommendations for the future work.

\section{RELATED WORKS}

The primary concern of well-prepared examination halls depends on the comprehensive distribution of examination seats. Allocation of the examination seats with unique number will ensure the distance among students can be controlled to avoid cheating by copying answers from their close friends (Chaki \& Anirban, 2016). The process of examination seat allocation starts as soon as the examination timetable of the courses is released. The tasks of examination timetabling and the seat allocation process are two different things (Burke, McCollum \& McMullan, 2006).

There are few solutions or techniques that have been proposed for examination seating number allocation. Kahar and Kendal (2010) provided a solution for the venue allocation or assignment at Universiti Malaysia Pahang, Malaysia They considered only one examination will take place in one room at a time. Nevertheless, this solution may create an opportunity to cheat in exam hall like copying from nearby students, which requires many examination venues and more invigilators. Furthermore, it will incur additional costs for such invigilation duty wages and utility such as electricity usage and light beverages for invigilators during the examination periods. Ayob and Malik (2011) done the same thing about the room assignment, but considered only special examination. This type of examination environment is easy 
to maintain, but cannot be tested with large numbers of enrolment, which requires more examination halls, courses and invigilators. The system should be able to cover and mostly focus on optimum uses of examination seats, having a standard distance of students getting the same set of question paper, avoiding the overlapping of seats and finally comprehensive seating arrangement that is comfortable for the students and invigilators (Chaki \& Anirban, 2016).

Who is responsible for the arrangement of examination seating number? This issue has been discussed either the seating numbers will be prepared using centralized or decentralized approach. Centralized examination seating number arrangement is prepared by the main department authority and this responsibility refers to Examination Department at the university level, while the decentralized examination seating number arrangement is arranged accordingly by the faculty or college (Wobmann, 2002). Most universities are unwilling to handle the centralized examination seating number arrangement because of increasing number of students, variety nature of the courses and special requirements from departments. It is quite difficult to properly allocate the seats among a large number of students whenever the students are from different courses and faculties. Majority of the education institutions practice the decentralized examination to avoid the hassles of seating number allocation preparation (Poala \& Scoppa, 2004).

The first pilot system for efficient seat allocation process has been proposed by Muhammad \& Elyas (2018). They created a preliminary plan for students from various fields or disciplines. Objectives of the project were to optimize a minimum number of chairs in the examination halls, provide a standard distance of seating plan in the examination halls to avoid cheating or copying answers from the nearby students as well as to avoid two or more students having the same seat numbers or overlapping during the examination. This way, students are able to check their seat numbers and examination venue before the examination day through online system. This really helps the students to plan earlier before they go to the examination halls. Before this, most of the students faced many problems finding examination venues as they knew their seating number 30 minutes before the examination starts. The class lists with complete seating numbers are pasted at the entrance of examination halls. With an innovative system, the class lists do not need to be pasted at the examination hall anymore. The system features allow the students to print the examination slips, which contain comprehensive examination information such as the date and time, venue and seating number for each course enrolled by each student. In addition, the system will navigate the student location of the seating number in the examination halls through their smart phone. The seating numbers are arranged according to students' name in alphabetical order and grouped by different types of course or subject.

The second project has been proposed and developed by group of students at A.V.C College of Engineering, Tamil Nadu, India (Ezhilarasi et. al, 2018). The objective of the system was to automate the process of assigning the examination venue and generate the seating numbers for each student. The system was developed using Visual Basic programming language and the database in Microsoft Access. Basically, the system runs as an offline platform. The system administration needs to distribute the printed examination slips from the system to each student, which contain complete information such as the examination date and time, venues and the seat numbers for each course.

The third similar project named Examination Seating Arrangement System (AU, 2014) has also been developed at Eden High School, Hong Kong, to arrange internal examinations automatically. The system was able to automate the seating arrangement and generate comprehensive examination slips similar to the first and second projects above. 


\section{PROPOSED WORK}

This section discusses the methodology applied in the development of automated examination seating number allocation and further clarifies the software and hardware requirements for this project. Detailed technique or approach required for this project is further explained at the end of this section.

The following Figure 1 below shows the proposed research methodology framework with six phases namely requirement analysis, system design, coding or implementation, integration and testing, system deployment and finally the maintenance. This framework was adapted from the Waterfall Model of System Development Life Cycle (SDLC) (Kenneth and Julie, 2014).

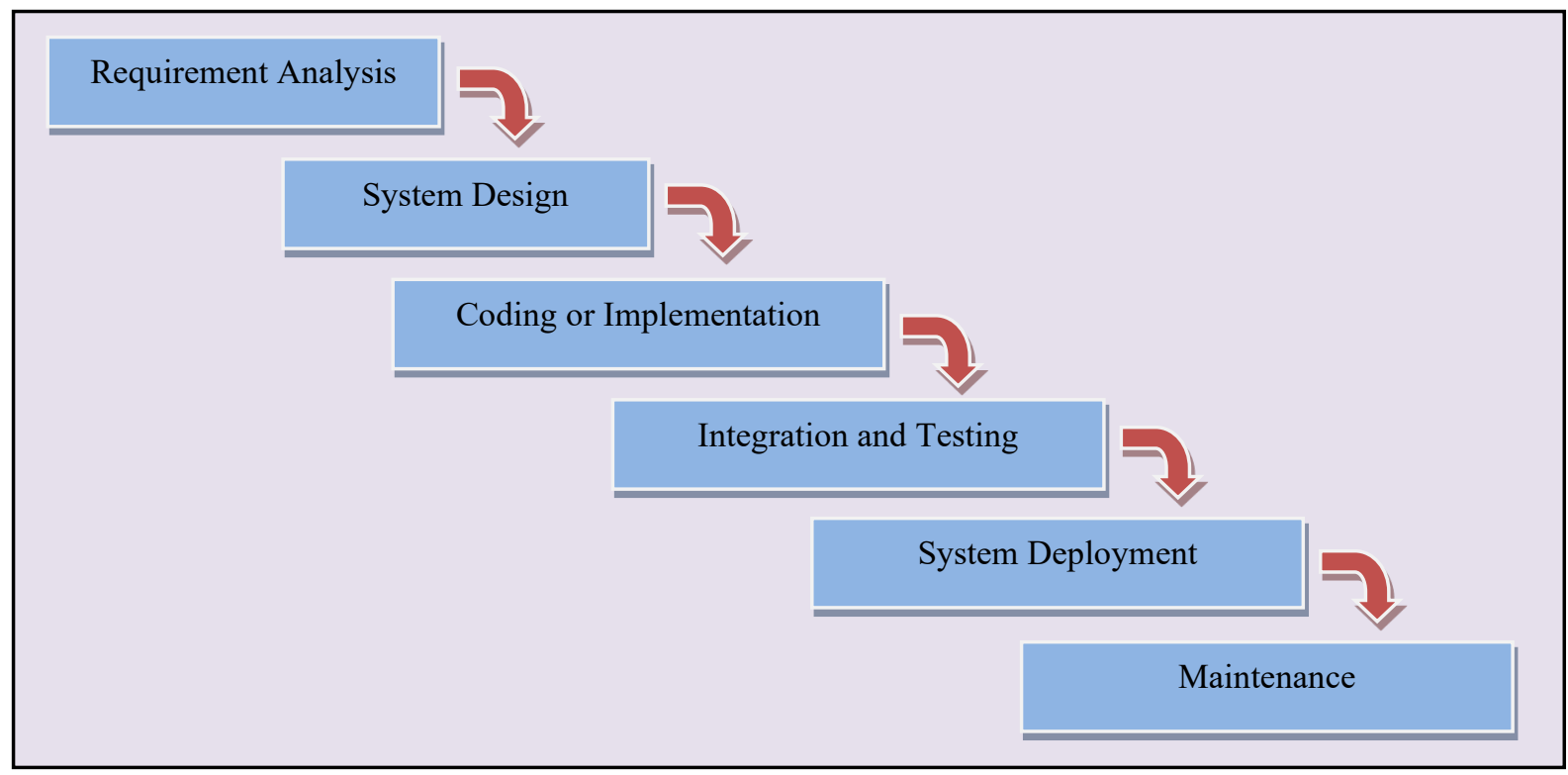

Figure 1: Research Methodology Framework, Waterfall Model of System Development Life Cycle (SDLC)

The waterfall model of SDLC is a sequential process in which its progress is seen as flowing steadily downwards like a waterfall through the phases. The first phase involves analysing and understanding the current systems. The system's specifications such as input, process and output (IPO) are also among the main focus in this phase. The purposes, scopes, objectives and functional requirements of the systems are needed to be proposed and confirmed before the systems design phase is started. The requirement specifications from the first phase are analyzed and studied during the system design. Activities involved are designing the algorithm and content ideas by reviewing the pseudo-code or flowchart to automate the allocation of seating numbers. System Design helps in specifying hardware and system requirements and in defining overall system architecture.

The third phase is implementation or coding whereby the documented design specifications from the second phase are coded using specified programming language and database management systems. The system is first developed in small programs called units, which are integrated into the next phase. Each unit is developed and tested for its functionality, which is referred to as Unit Testing. Integrating testing is the fourth phase in which all the units developed during the implementation phase are integrated into a system. The software needs to go through thorough software testing to find out any conscious and unconscious errors. The functional and non-functional testing are done by the users and developers so that they do not face any problem during the software deployment. Functional testing mainly refers to the system requirements confirmed by the users, while the non-functional requirement is related to technical requirements such as the hardware, network and security aspects. 
Once the functional and non-functional testing is successfully done, the product is deployed in the client environment or released into the market. System deployment is the phase prior to system maintenance. The maintenance phase involves making modifications to the system or an individual component to alter attributes or improve performance. These modifications arise either due to changed requests initiated by the users, or defects uncovered during live use of the system. The user is provided with regular maintenance and support for the software. Maintenance is also the activity of improvising the system to sustain the users' acceptance, meet the goals of the project and fulfils the ad hoc requirements raised by the users.

The task of seating number allocation started whenever the Academic Evaluation Department at UiTM Shah Alam releases the finalized examination schedules to all campuses and faculties. Examination Unit staff at each campus and faculty downloads the students' enrolments from the Student Integrated Managements Systems (SIMs). Once the enrolments are downloaded, the records are crossed linked with the records of examination schedules through the Examination Management Systems (EMS). Next, the crossed linked records are auto assigned with examination venues before the seating number allocation process is started. The following Figure 2 shows the framework of Examination Management System (EMS) operations.

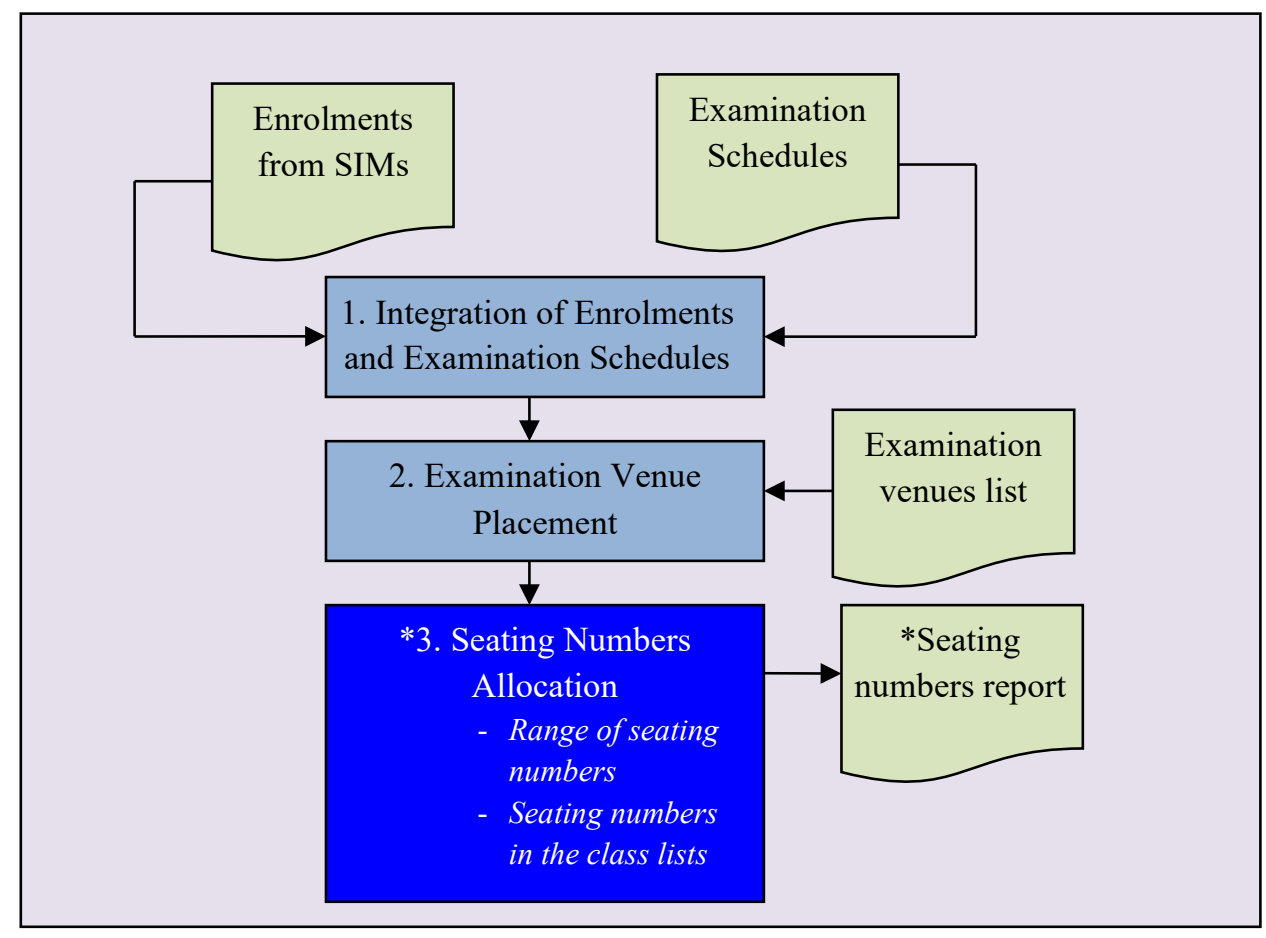

Figure 2: Framework of Examination Management System (EMS) with Seating Number Allocation Module (*new module)

The first and second tasks of Figure 2 are auto generated by EMS. The third task is the new module embedded as part of EMS module. This new module encompasses two sub modules; the first sub module generates the range of seating numbers according to the groups of each course in the examination hall. The second sub module sequentially assigns the seat number in the class lists of the group for each student according to the seating number range allocated and generated in the first sub module.

Special techniques including nested repetitive structures were applied for both sub modules. To test and verify the effectiveness of this technique, real data of students' enrolments and examination schedules were taken from the Student Information Integrated System (SIMs). The data were taken from two 
consecutive examination sessions; June 2019 and December 2019 academic semester. The following figures are the sample of enrolments (Figure 3), examination schedules (Figure 4) and the examination venues list records (Figure 5) taken during December 2019 examination.

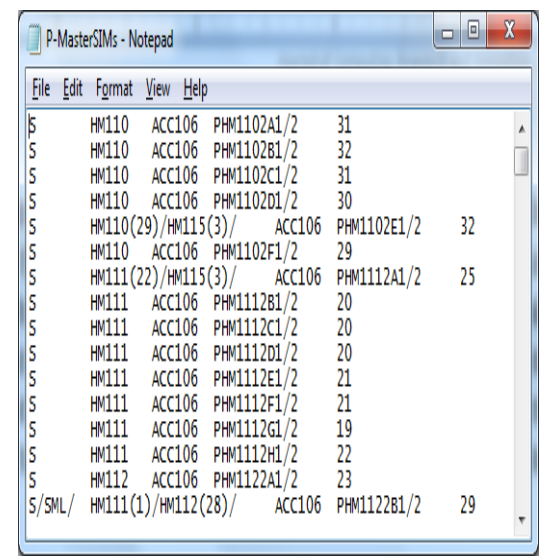

Figure 3:

Enrolments Records

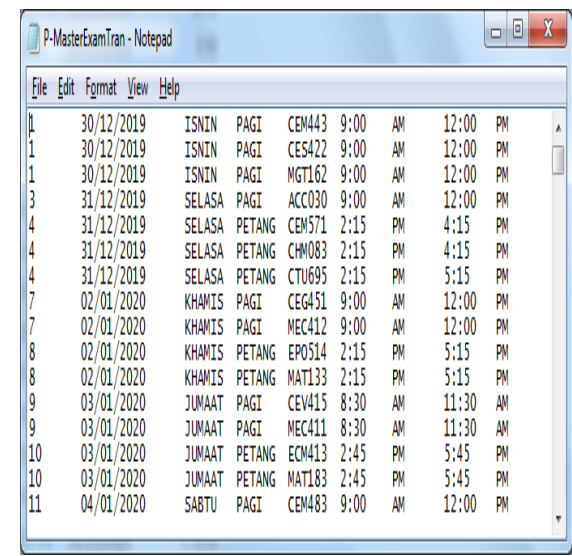

Figure 4:

Examination Schedules Records

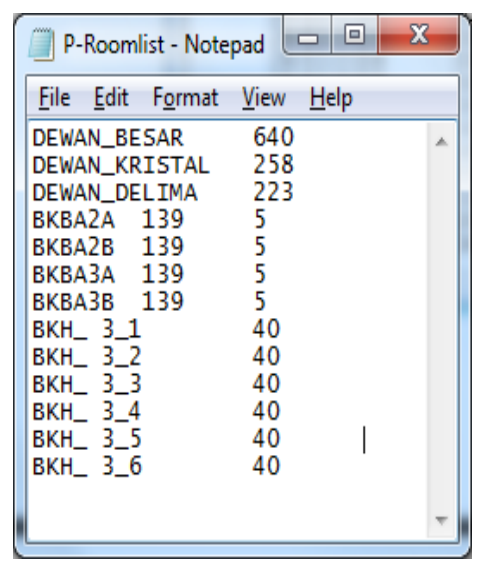

Figure 5:

Examination Venues Records

Figure 6 show the cross link of enrolments and examination schedules records while Figure 7 is the cross linked records (from Figure 6) that have been allotted with the examination venues.

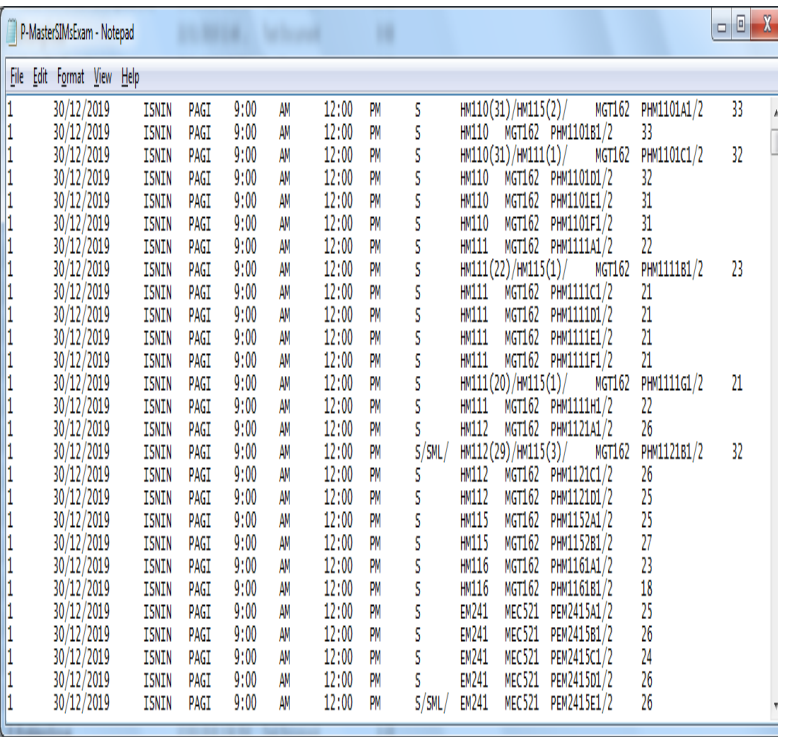

Figure 6 :

Cross Linked of Enrolments \& Examination Schedules

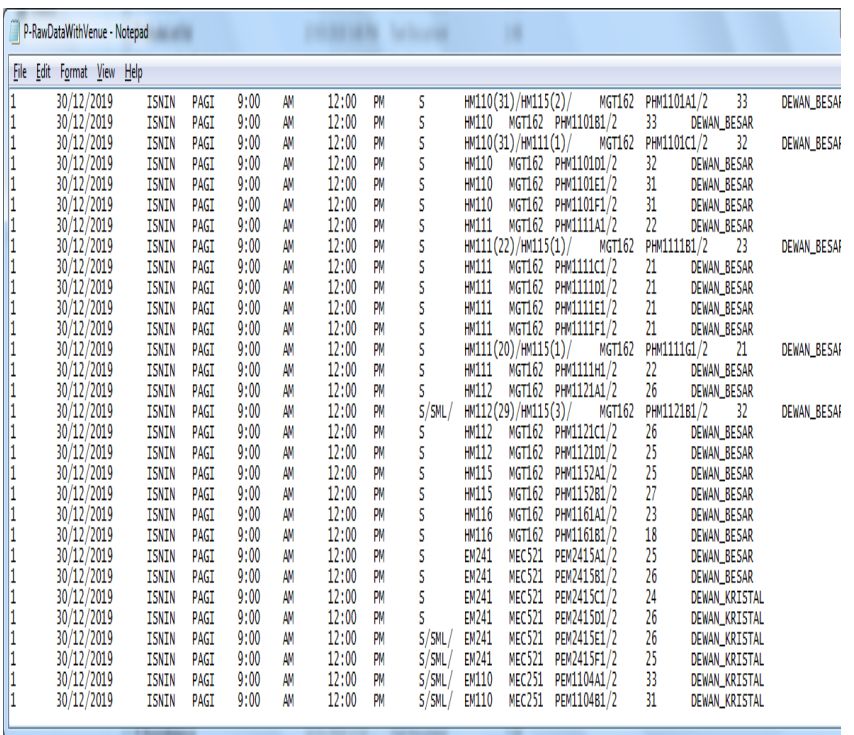

Figure 7:

Records with Examination Venue

An algorithm of Nested Repetitive Techniques was designed and coded using JAVA programming language and operated under Windows 7 or higher version of windows operating system. Normal personal computer or laptop can be used to operate this application program. The algorithm considers no issues of overlapping seat numbers among the students, no cases of overloaded problem in the examination halls and extra seats are always available if there is a case of special students without the seat numbers are allocated to him. Figure 8 shows the algorithm of nested repetitive technique to generate the range of seating numbers. 


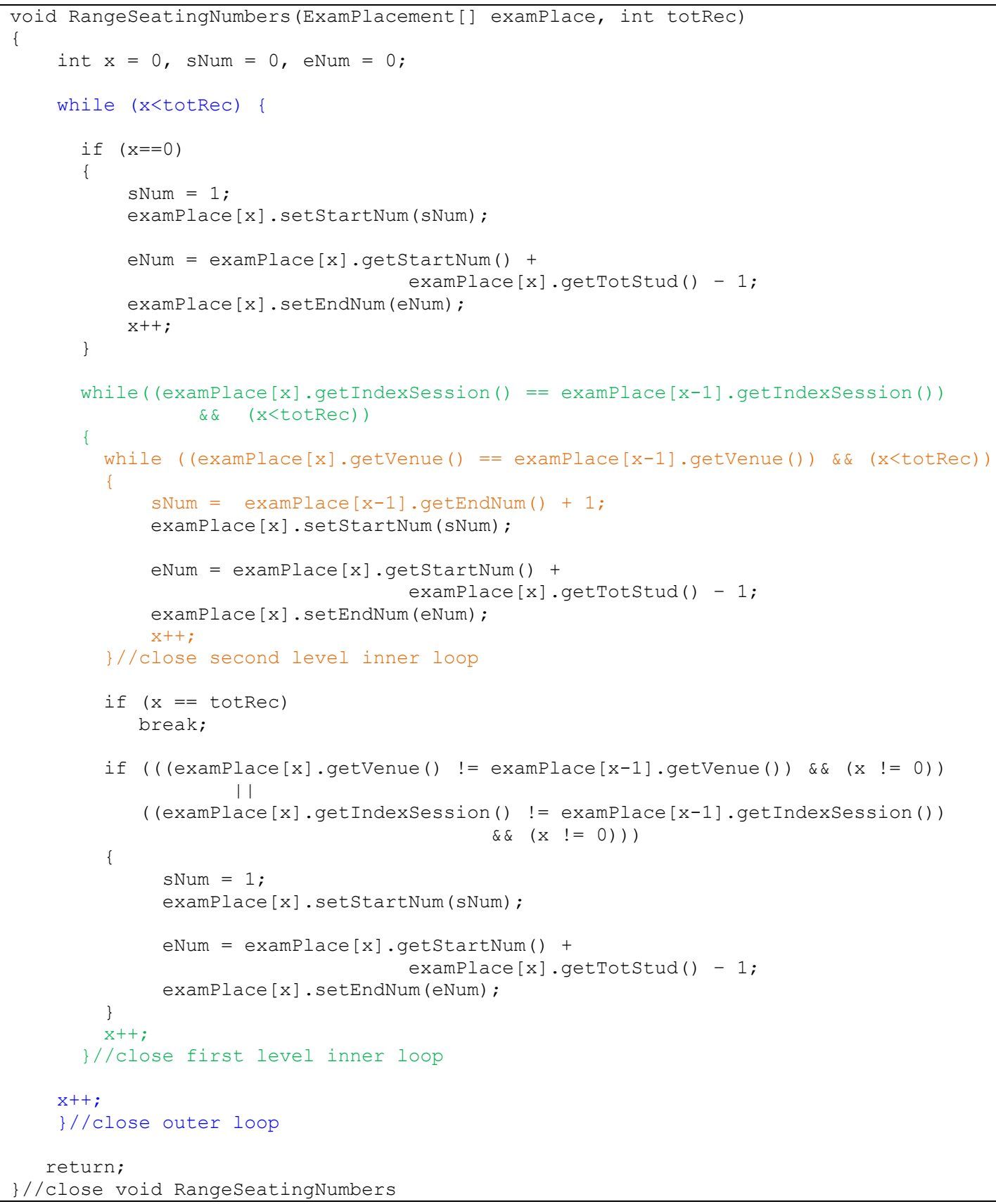

Figure 8: An Algorithm of Nested Repetitive Techniques for the Range of Seating Numbers

The following Figure 9 shows the nested repetitive technique for assigning seat numbers to each student based on the seating number range allocated by algorithm in Figure 8.

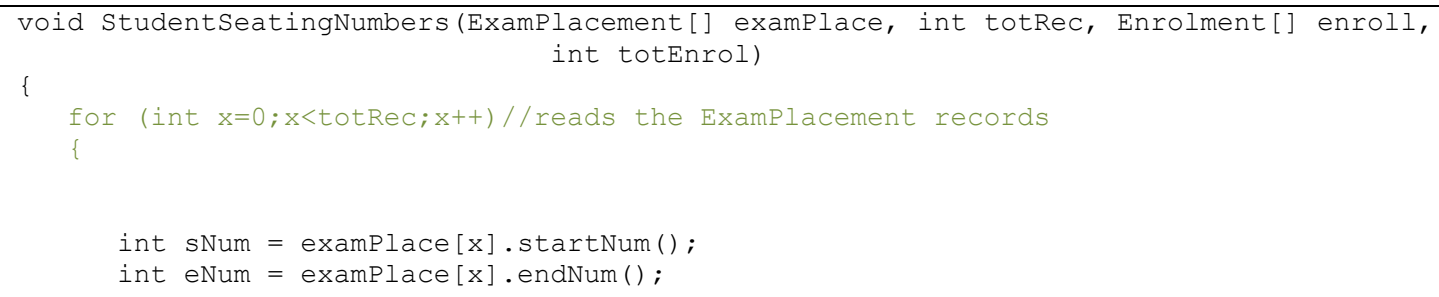




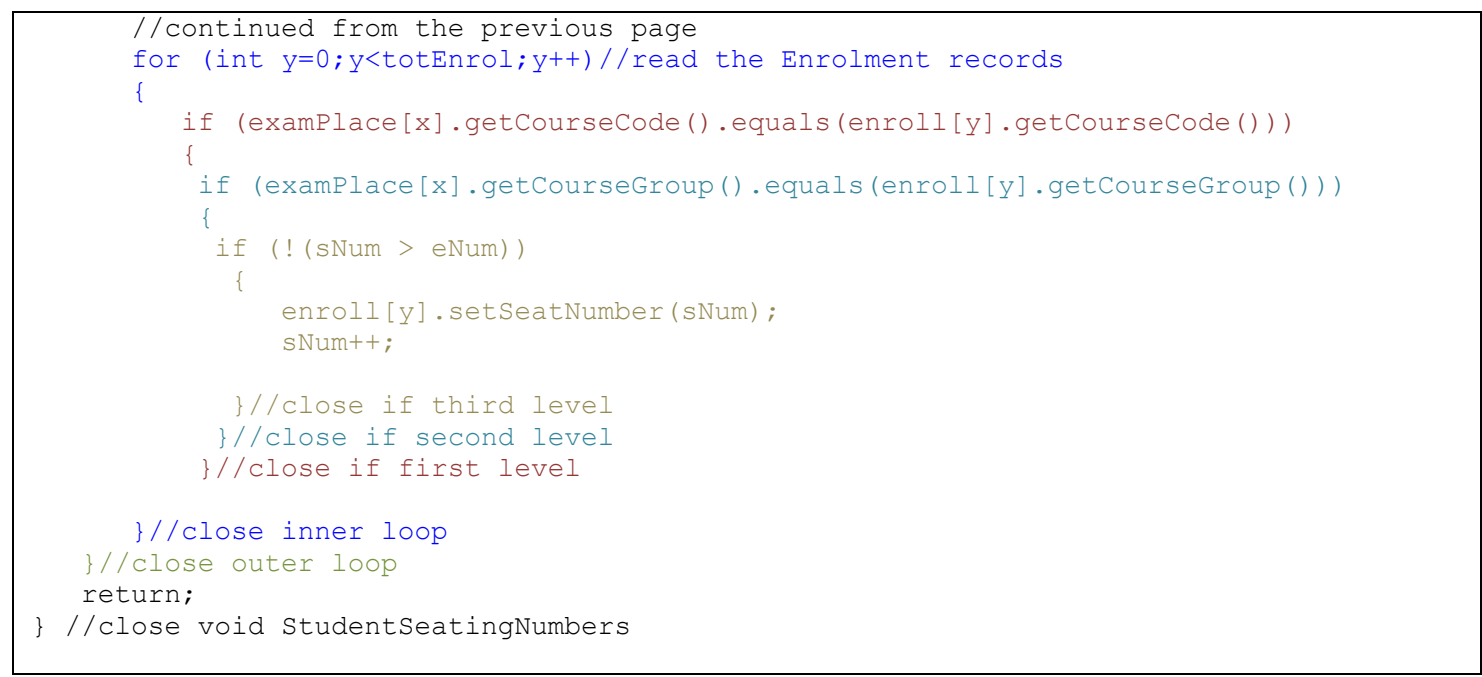

Figure 9: An Algorithm of Nested Repetitive Techniques for Assigning the Seat Number to Each Student

The algorithm from Figure 8 was used to generate the range of seating numbers before the algorithm of Figure 9 was applied to allocate the seat numbers for each student. Both algorithms were developed using JAVA programming language and embedded in the Examination Management Systems (EMS). These two algorithms are related to each other because the records processed in the first algorithm (Figure 8) were further processed in the second algorithm (Figure 9).

\section{RESULTS AND FINDINGS}

The students' enrolments and examination schedules records in Jun 2019 and Dec 2019 sessions were used to test the effectiveness of both algorithms. The following Figure 10 shows the last two columns of each record that has successfully assigned the start and end numbers of seating number range. The following is the standard report generated from Examination Management System (EMS).

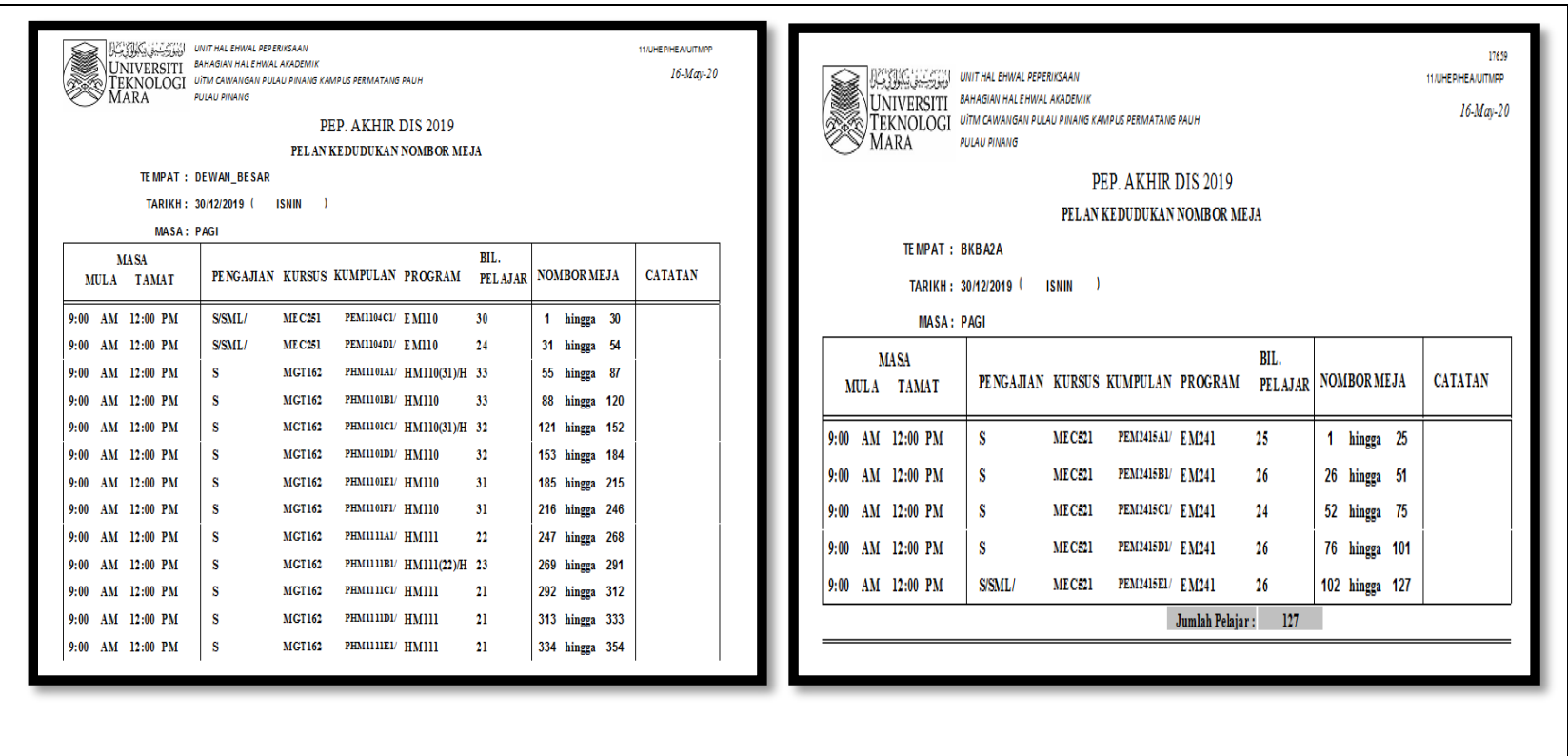

Figure 10: Range of Seating Numbers were Successfully Assigned at Two Different Venues in the Morning session for the First Day of Examination 
The algorithm has also successfully assigned the range of seating numbers to all slots of examination for three weeks of examination including the location of examination, courses and the students' groups. The following Figure 11 illustrates the next slots of examination, which are in the afternoon session.

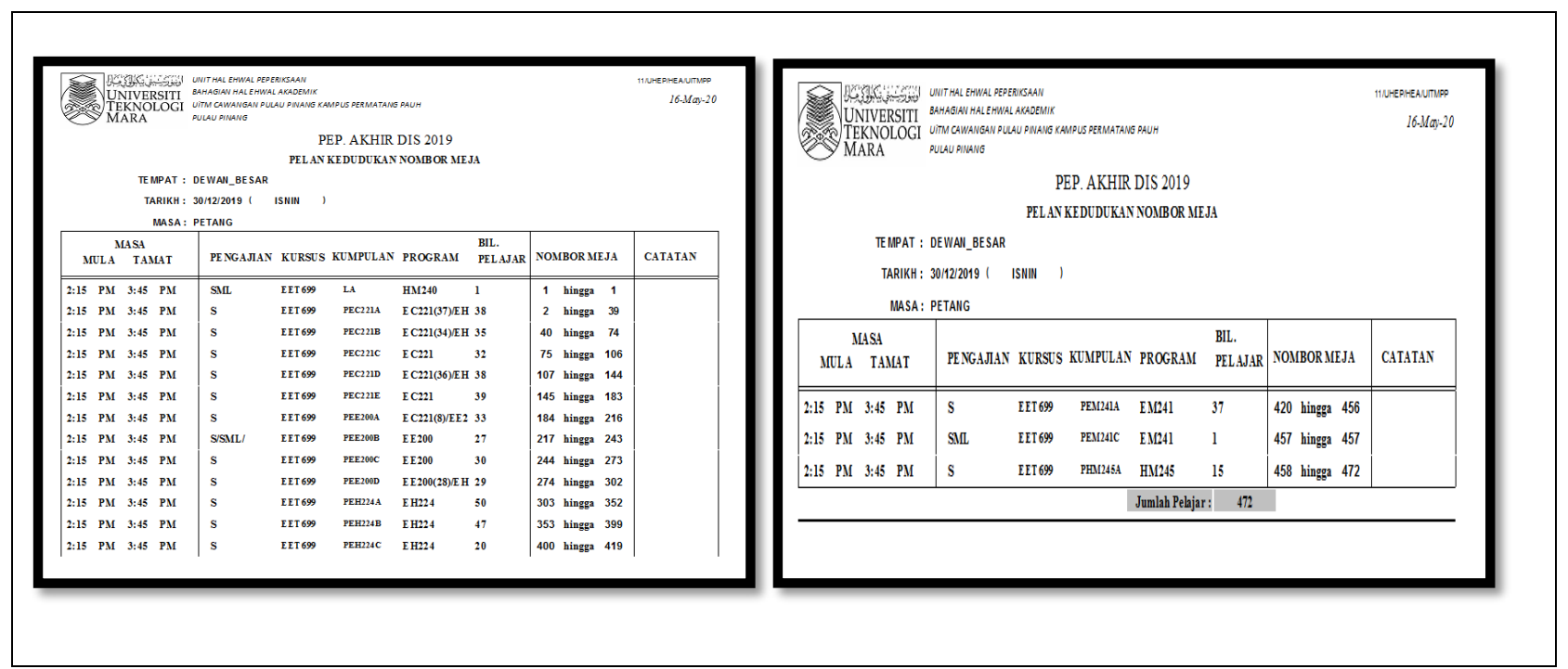

Figure 11: Range of Seating Numbers in Afternoon Session for the First Day of Examination at Dewan Besar

The second algorithm was used to assign the seat number for each student by group of the course. The following Figure 12 displays the report generated from the Examination Management Systems (EMS) after the second algorithm was executed. The following report showed that the seat numbers were assigned sequentially from the start number until end number of the range where the names of the students were sorted in alphabetical order.

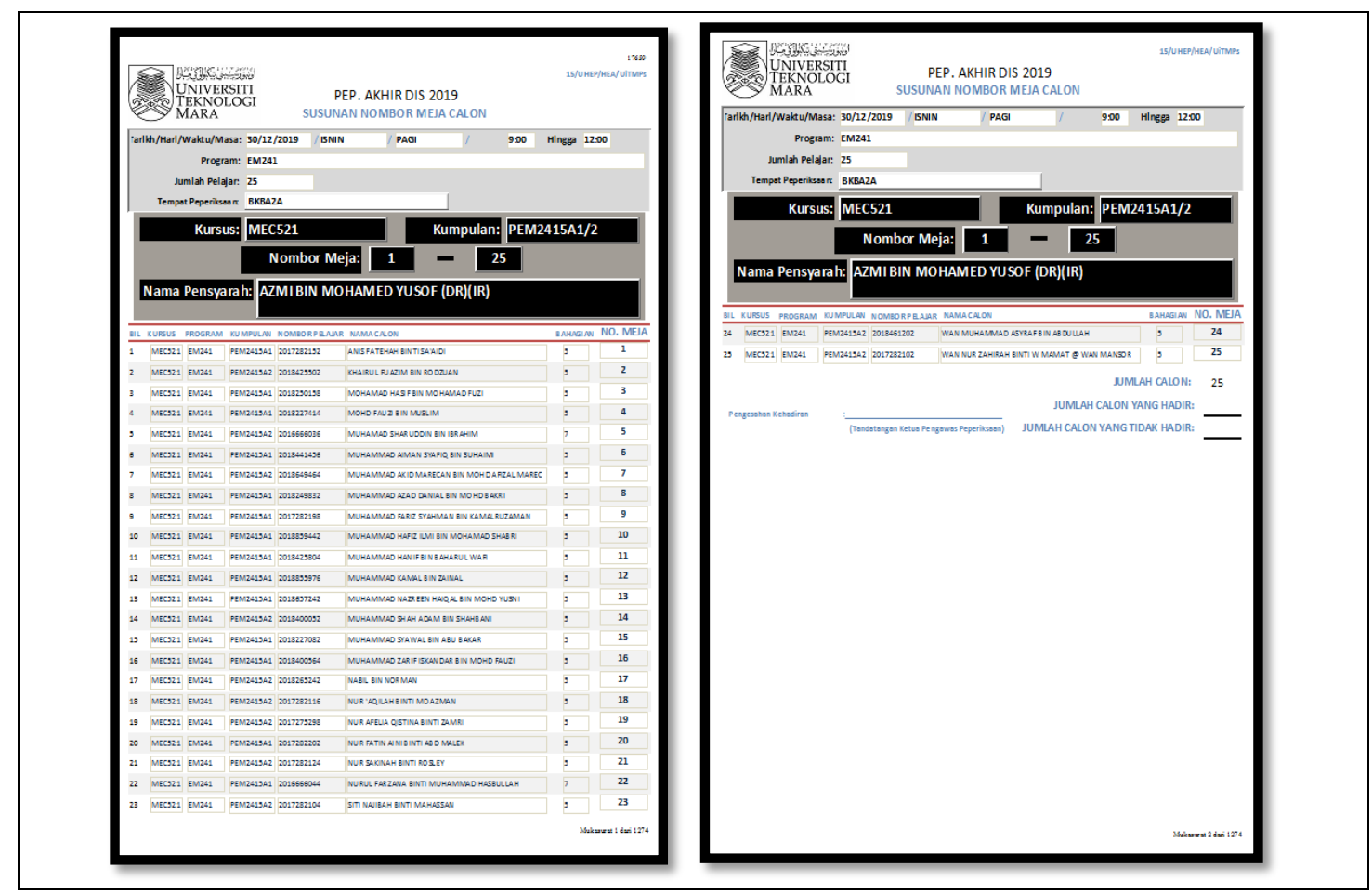

Figure 12: Each Student is Assigned with the Seat Numbers Sequentially 
The techniques used to test the functionality of both algorithms were unit testing and integration testing. Unit testing is a practical approach to increase the correctness and quality of a software (Cheon \& Leavens, 2001). Unit testing is based on the structural view into the implementation code. Code coverage tools can be used to provide the programmer with insight into which part of the code structure has been tested (Runeson, 2006). Meanwhile, integration testing is used to uncover errors in the interactions between system units or modules. It focuses on testing the connections presumed to be more error-prone (Banitaan et al., 2017). The testing techniques applied to both algorithms showed no errors in the report generated in Examination Management Systems (EMS). The following Table 1 shows the testing results of execution for seating numbers range algorithms using the real data of two sessions of final examination academic sessions.

Table 1: Testing Results of Execution for Seating Numbers Range Algorithms

\begin{tabular}{llllll}
\hline $\begin{array}{l}\text { Examination } \\
\text { Academic Sessions }\end{array}$ & Total Records & $\begin{array}{l}\text { Total } \\
\text { Assigned the Table Seating Range }\end{array}$ & $\begin{array}{l}\text { Records } \\
\text { Successfully } \\
\text { Detected }\end{array}$ & Error & Records \\
\hline December 2019 & 730 & 730 & None \\
June 2019 & 641 & 641 & None \\
\hline
\end{tabular}

The same testing techniques have been done to the second algorithm to examine effectiveness of assigning the seat numbers to each student. The following Table 2 shows the results of the execution using the same real data of two sessions of final examination academic sessions.

Table 2: Testing Results of Execution for Assigning Seat Numbers Algorithms

\begin{tabular}{llllll}
\hline $\begin{array}{l}\text { Examination } \\
\text { Academic Sessions }\end{array}$ & $\begin{array}{l}\text { Total Records } \\
\text { of Enrolment }\end{array}$ & $\begin{array}{l}\text { Total } \\
\text { Assigned the Seating Numbers }\end{array}$ & $\begin{array}{l}\text { Records } \\
\text { Successully }\end{array}$ & $\begin{array}{l}\text { Total Error } \\
\text { Detected }\end{array}$ & Records \\
\hline December 2019 & 17659 & 17659 & None & \\
June 2019 & 15487 & 15487 & None \\
\hline
\end{tabular}

Both algorithms have successfully assigned the range of seating number at the examination venues and seat numbers to each student, respectively. The algorithms have solved issues such as overloaded students after assigning the seat numbers, clashes of the same seat numbers, mistakenly unassigned seat numbers and unstructured order of the students' sequence in the examination halls. The Examination Unit staff and examination committee members responded positively to the new application system since it has solved a lot of their workloads. Their job specifications were reviewed and currently, their only tasks left were to examine and verify the report of seating numbers generated through the Examination Management Systems (EMS). Once the report is verified and approved by the Executive Officer, it will be released to the students. The students will be able to check their seat numbers for each course through the online system earlier before the examination. The following Figure 13 shows an example of student's examination profile complete with the examination venue and the seat numbers for each course.

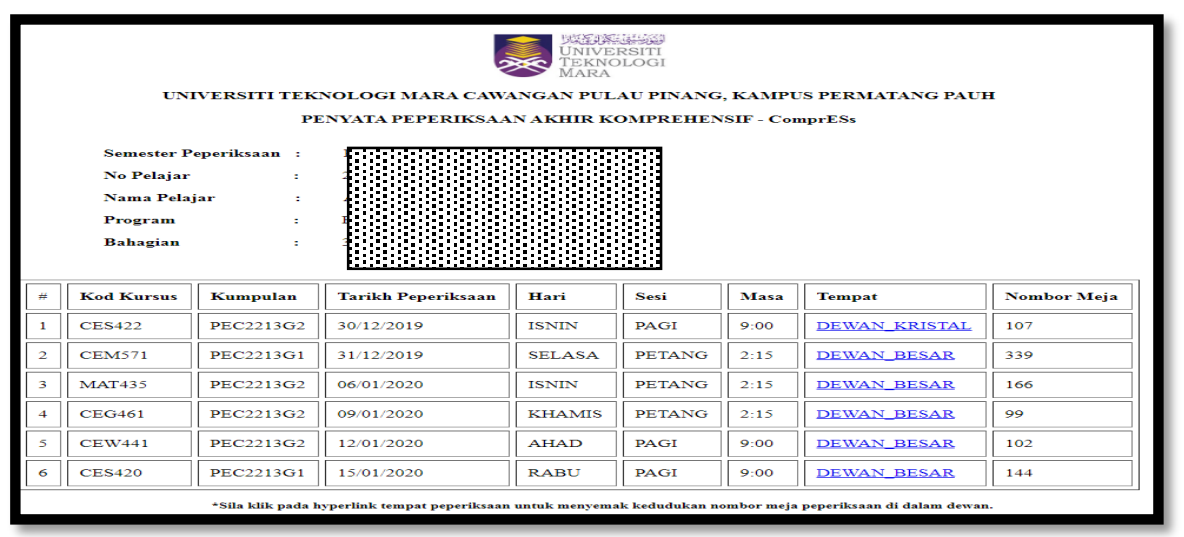

Figure 13: Student's Examination Profile 
Through the hyperlinks of examination venue as shown in Figure 13, the student will be self-guided through their smart phones to the location of the seat number in the examination hall as shown the Figure 14. This feature will improve examination operation efficiency especially at venues with a large capacity.

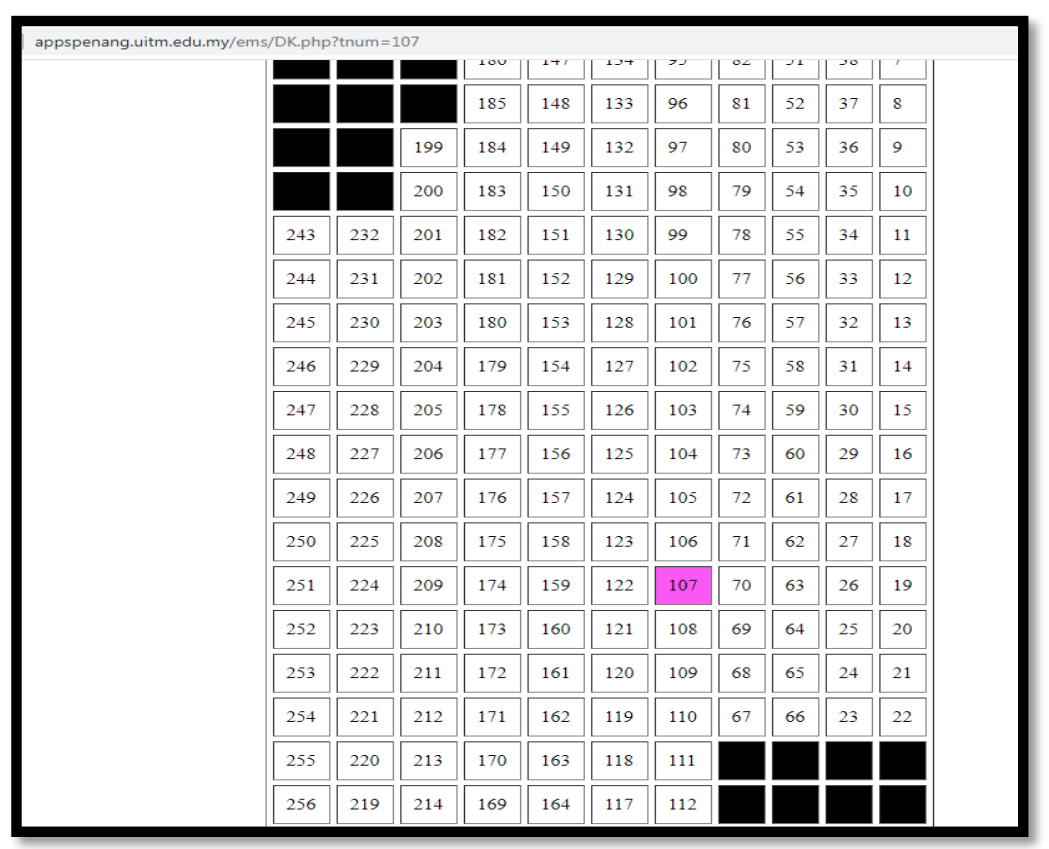

Figure 14: Examination Venue Plan with the Highlighted Location of the Seat Number

\section{CONCLUSION AND FUTURE WORK}

Examination Management Systems (EMS) has been able to improve the efficiency and effectiveness of examination administration. The application had decreased the resources needed to accomplish the task (Bhardwaj \& Singh, 2011). The Examination Unit staff and examination committee members were proudly satisfied with the application system because the burden of manual preparation of the examination seating numbers arrangement have been took over by the application system. Their job specifications have been reviewed and they were able to focus much more on the efficiency and integrity aspects of examination operations. This will reduce the risk of mismanagement during examination operations (Muhammad \& Elyas, 2018). In addition, the system has reduced the duration of seating number manual preparation from three weeks to less than 1 minute. Consequently, the reduction of overtime claimed among staff is expected once the system is implemented. In addition, the students praised the website of Examination Management System (EMS) for helping them in knowing the examination schedules earlier, which is also accessible anywhere and anytime. The students responded that the web provides comprehensive examination information.

Planning for the future work, the algorithms as introduced in this paper will be tested at other campuses of Universiti Teknologi MARA (UiTM). The algorithms will be enhanced and improvised repeatedly until it achieves the optimized standard of algorithm that can be flexibly applied at any situation and condition. The enhancement of EMS is an on-going process whenever there are suggestions or positive comments given by the users or Examination Unit staff as well as through benchmarking platforms by other UiTM campuses, faculties and local or private universities. Thus, for the improvement of EMS, the Examination Unit will continuously support the operation of EMS and ensure the good rapport. Nested Repetitive Technique is just the beginning of the journey. In the future, it is hoped that there will be more innovative 
ideas to further improvise the algorithm to become an outstanding approach in the process of examination seating number arrangement.

\section{REFERENCES}

Au, E., (22 Jan 2014). Examination Seating Arrangement System, Hong Kong School Internal Exam. Seating Arrangement System (ESAS), Retrieved at https://edenau.github.io/exam-sitting.

Ayob, M. and Malik, A. (2011), A New Model for an Examination-Room Assignment Problem, International Journal of Computer Science and Network Security (IJCSNS), Vol.11 No.10.

Banitaan, S., Nygard, K. E., Magel, K. (2017), Test Focus Selection for Integration Testing, Journal of Software Engineering and Knowledge Engineering, Vol. 27, No. 08., pp. 1145-1166 (2017).

Bhardwaj, M., and Singh, A. J. (2011). Automated Integrated University Examination System. Himachal Pradesh University Journal, 1, 156-162.

Bloomfield, S.D., McSharry, M.M. (1979). Preferential Course Scheduling. 9(4), 24-31.

Burke, E.K., McCollum, B., and McMullan, P. (2007). Examination Timetabling: A New Formulation, International Conference on the Practice and Theory of Automated Timetabling (PATAT 2006), Brno, Czech Republic, ISBN : 80-210-3726-1.

Chaki, P.K., and Anirban, S. (2016), Algorithm For Efficient Seating Plan For Centralized Exam System, International Conference on Computational Techniques in Information and Communication Technologies (ICCTICT), ISBN : 978-1-5090-0082-1.

Cheon, Y. and Leavens, G.T. (2001), A Simple and Practical Approach to Unit Testing : The JML and JUnit Way, Computer Science Technical Reports, 181, http://lib.dr.iastate.edu/cs_techreports/181.

Ezhilarasi, V., Sujitha, S., Vennila B. and Archana, M. (2018), Design and Implementation of Automatic Exam Pre-processing System, International Journal of Scientific Research in Computer Science, Engineering and Information Technology (IJSRCSEIT), Volume 3, Issue 1, ISSN : 2456-3307.

Kahar, M.N.M. and Kendall, G. (2010), The Examination Timetabling Problem at Universiti Malaysia Pahang: Comparison of a Constructive Heuristic With an Existing Software Solution, MIT Press and McGraw-Hill, ISBN : 0-262-03141-8.

Muhammad, R.C.K. and Eliyas, S. (2018), Efficient Seat Allocation Process in College Examination System, International Journal for Research in Applied Science \& Engineering Technology (IJRASET), Volume 6 Issue V, May 2018, ISSN: 2321-9653.

Paola, M. D. and Scoppa, V. (2004), A signalling model of school grades: centralized versusdecentralizedexaminations,JEL Classification: D02, H42, I28.

Quality (2010), Quality Manual of UiTM CawanganPulau Pinang, ISO 9001:2008.

Runeson, P. (2006), A Survey of Unit Testing Practices, IEEE Software, no. pp. 22-29.

UiTM (2016), Examination Procedures Manual, Academic Assessment Division of UiTM. 
Wobmann, L. (2002), How Central Exams Affect Educational Achievement: International Evidence from TIMSS and TIMSS-Repeat, Harvard University Program on Education Policy and Governance Working Paper No. PEPG/02-10. 